\title{
EXPLORING HOW DESIS IMAGERY CAN ENHANCE THE CHARACTERIZATION OF LAND SURFACE PHENOLOGIES IN MONTANE PASTURES
}

\author{
G. Henebry ${ }^{1,2 *}$, M. Tomaszewska ${ }^{1}$, M. Zhumanova ${ }^{1}$, A. Mambetov ${ }^{3}$, S. Orunbaev ${ }^{3}$, Z. Kulenbekov ${ }^{3}$ \\ ${ }^{1}$ Center for Global Change and Earth Observations, Michigan State University, East Lansing, MI, 48823 USA - (monikat, \\ zhumanov)@msu.edu \\ ${ }^{2}$ Dept. of Geography, Environment, and Spatial Sciences, Michigan State University, East Lansing, MI, 48824 USA - \\ henebryg@msu.edu \\ ${ }^{3}$ Dept. of Applied Geology, American University of Central Asia, Bishkek, KG - (mambetov_a, orunbaev_s, \\ kulenbekov_z)@auca.kg \\ Commission I, WG I/1
}

KEY WORDS: VEN $\mu$ S, Kyrgyzstan, scaling, grasslands, seasonality, Central Asia.

\begin{abstract}
:
DESIS products offer information-rich images, but these data are rarely acquired for most sites. We explored how these image "jewels" fit within dense image time series of higher spatial resolution but lower spectral resolution data to enhance the characterization of the land surface phenologies exhibited by montane pastures in central Kyrgyzstan. We used surface reflectance data at $5 \mathrm{~m}$ spatial resolution from the French-Israeli VEN $\mu$ S mission over the NARYN intensive observation site from 2019 and 2020. Upon evaluating the quality of the DESIS data, we found substantial geolocation problems in multiple images and limitations in some of the Quality-2 masks. Here we have reported on these problems and focused analysis on the DESIS images from 2020 that substantially overlap the NARYN footprint, occurred during the growing season, and had sufficiently low cloud cover to enable comparisons. We calculated multiple vegetation indices enabled by the spectral resolution of the VEN $\mu \mathrm{S}$ bands, having averaged the DESIS bands to correspond to the VEN $\mu S$ bands. Of the 12 ground locations we had sampled in July 2021, just four locations had sufficient DESIS data in 2020 to characterize the growing season. Comparison of the higher spatio-temporal resolution of the VEN $\mu \mathrm{S}$ data with the lower spatio-temporal resolution of the DESIS data revealed that DESIS can capture the broad outlines of land surface phenology and spatial heterogeneity of the landscape with responses comparable to VEN $\mu$ S, but it could not reveal the finer temporal resolution of transhumance dynamics. DESIS data merit further analysis in other highland pasture areas.
\end{abstract}

\section{INTRODUCTION}

Rural communities rely on montane pastures to support the agro-pastoralist livelihoods that form the foundation of rural economies in Kyrgyzstan, Tajikistan, and other areas of montane Central Asia. However, regional climate change threatens these livelihoods (de Beurs et al., 2018; Groisman et al., 2018; Tomaszewska and Henebry, 2018).

The recent literature on montane pasture degradation in Central Asia has focused on coarser spatial resolution imagery (Dubovyk et al., 2016; Kulikov et al., 2016; Wang et al., 2020; Zhumanova et al., 2018). However, terrain factors and land use gradients evident at finer spatial scales complicate inferences about pasture degradation based on data from sources like MODIS (Tomaszewska et al., 2020; Tomaszewska and Henebry, 2021).

Here we explore how DESIS data can enhance characterization of the spatial heterogeneity of land surface phenologies in montane pastures by leveraging a high spatial and temporal resolution dataset from the French-Israeli $\mathrm{VEN} \mu \mathrm{S}$ mission, which is available over a limited area in eastern Naryn oblast of central Kyrgyzstan from 2018-2020. Specifically, we are interested whether DESIS can provide a visualization of the pasture landscape that is comparable to that imaged by the much higher spatial resolution $\mathrm{VEN} \mu \mathrm{S}$ data.

\section{STUDY AREA}

The study area is in Naryn oblast in central Kyrgyzstan, Specifically, the VEN $\mu \mathrm{S}$ intensive observation site is located east of Naryn city (Figure 1). The $\mathrm{VEN} \mu \mathrm{S}$ footprint of the
NARYN intensive observation site is approximately $27 \mathrm{~km}$ cross-track by $54 \mathrm{~km}$ along-track.

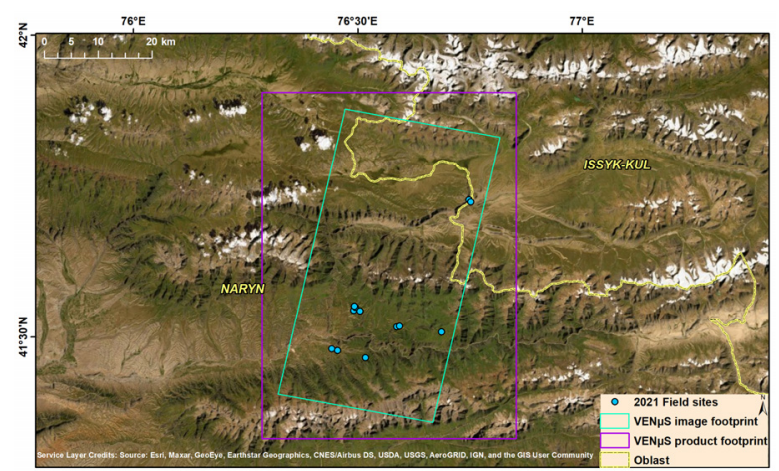

Figure 1. Study location in Naryn oblast, central Kyrgyzstan.

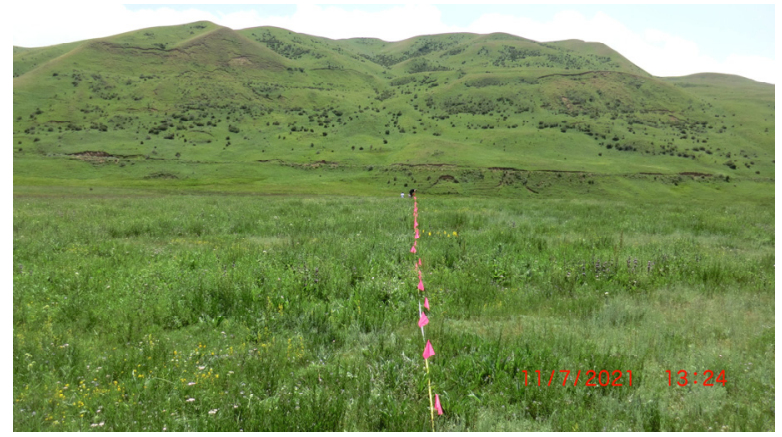

Figure 2. View of transect N01 showing a transitional pasture. 


\section{DATA \& PROCESSING}

3.1 Ground data: In July 2021, our team sampled 12 sites (cyan circles in Figure 1; view of a transect at N01 shown in Figure 2) within the NARYN VEN $\mu$ S footprint using paired orthogonal $100 \mathrm{~m}$ transects to characterize plant community, pasture health, and subpixel heterogeneity. However, no ground-level spectral data were available from 2020 or 2021. Here we use the GPS coordinates of the transect centers and information about the seasonality of pasture use at these locations: either transitional pastures - used in spring and again in fall—or summer pastures.

3.2 VEN $\mu$ S data: As result of an international competition held in 2015, VEN $\mu \mathrm{S}$ data were acquired at the Naryn site from 2018 to 2020 . The VEN $\mu$ S data over Naryn that were available to compare with DESIS included 47 scenes in 2019 and 46 in 2020 at $5 \mathrm{~m}$ spatial resolution and in 12 spectral bands. The "flat" surface reflectance product was used in our analyses. Figure 3 shows the temporal distribution of VEN $\mu$ S and DESIS data in 2020 for the 12 transects within the footprint.

We calculated four vegetation indices to facilitate the comparison of VEN $\mu \mathrm{S}$ and DESIS data: (1) NDVI for reference; (2) anthocyanin index (Gitelson et al., 2006), which is sensitive to plant stress; (3) red-edge chlorophyll index tuned for erectophile canopies (Clevers and Gitelson, 2013), which is more sensitive than NDVI to canopy differences; and (4) chlorophyll/carotenoid index for MODIS bands (Gamon et al., 2016; Wang et al., 2020), which is sensitive to seasonal dynamics in coniferous canopies.

\section{DESIS_VENHS NDVI 2020}

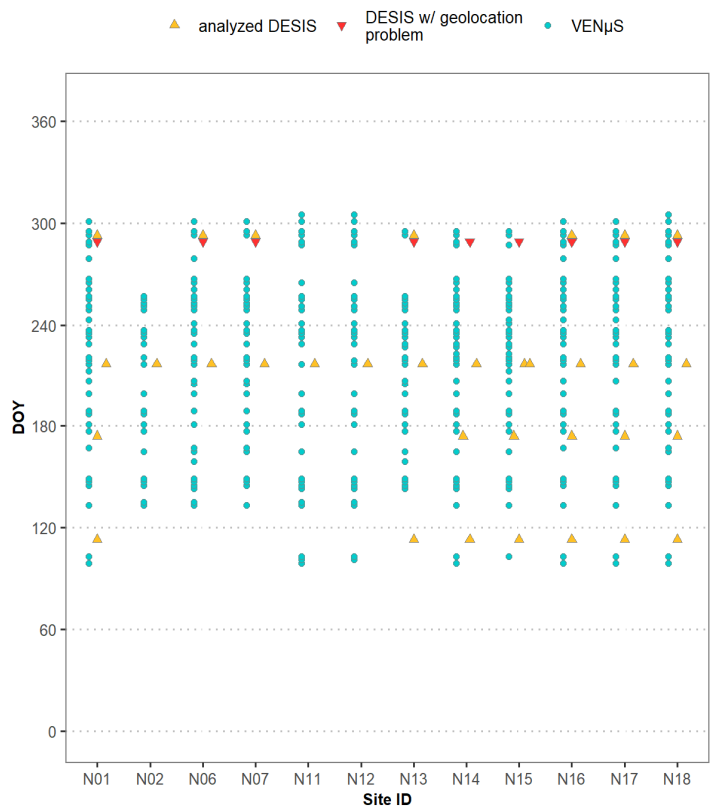

Figure 3: VEN $\mu$ S and DESIS data over NARYN in 2020.
3.3 DESIS data: As part of NASA's engagement with the DESIS mission, we requested in February 2019 acquisitions over eastern Naryn oblast with a particular emphasis on the growing season. We downloaded the 40 available scenes overlapping the VEN $\mu \mathrm{S}$ footprint during 2019 to 2020. We evaluated them visually, filtered out low quality pixels using the Quality-1 band-specific flags, and applied the following Quality-2 masks: $1,4-7=0$, and $2=1$. We did not apply the snow mask (layer 3) because we wanted to see the sensor response in the snowy areas and those areas were far from the pasture areas of interest. We simulated the VEN $\mu \mathrm{S}$ data by simply averaging the DESIS bands corresponding to the VEN $\mu \mathrm{S}$ bands.

3.4 MODIS data: We used version 6 of the MODIS land surface temperature products (MOD11A2 and MYD11A2) to calculate the accumulated growing degree-days (AGDD) with base temperature of $0^{\circ} \mathrm{C}$ (Tomaszewska et al., 2020). Temperate grasslands have been shown to exhibit land surface phenology that is well-articulated as a quadratic function of AGDD (Tomaszewska et al., 2020).

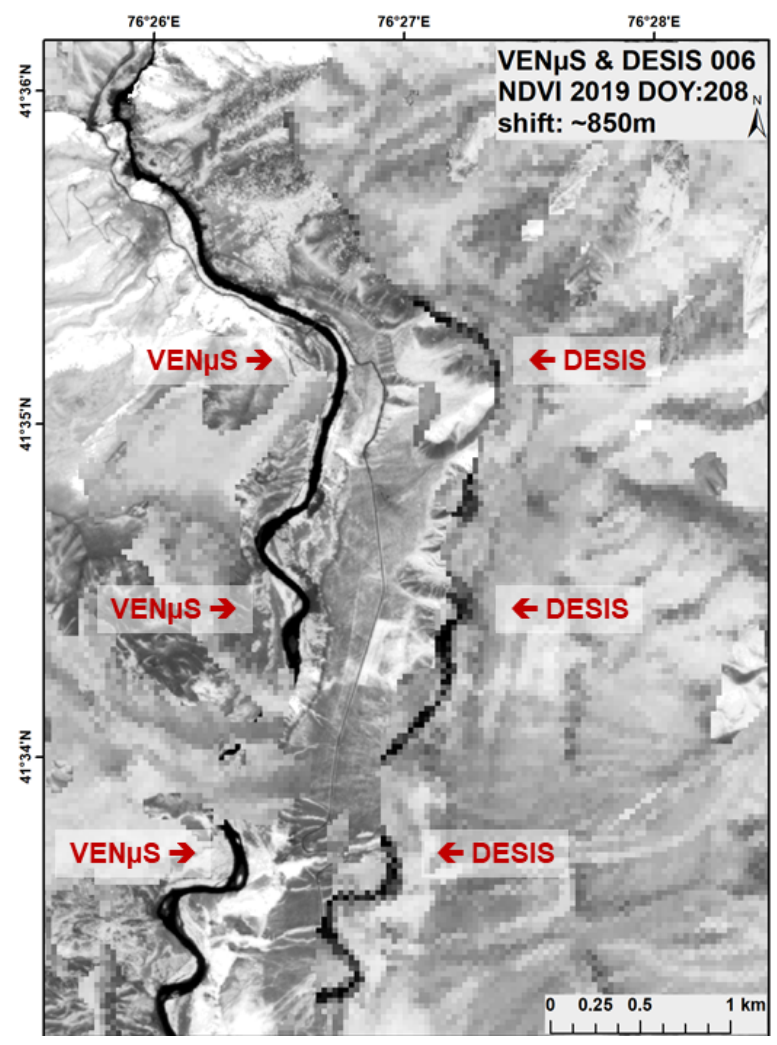

Figure 4: Example of a severe DESIS geolocation error. In this composite the georeferenced DESIS data appears shifted to the east (right) relative to the correctly georeferenced VEN $\mu \mathrm{S}$ data appearing at left. The labels point to some of the spatial discrepancies arising from geolocation error and the coarser spatial resolution of the DESIS. 


\section{RESULTS \& INTERPRETATION}

4.1 Geolocation errors: On inspection several DESIS images had severe geolocation errors (Figure 4). Upon inquiring to user support about this issue, Heath Lester of Teledyne Brown Engineering explained that the default image matching algorithm had failed in these instances due to a combination of cloud cover and differences in shadow patterns in the rugged terrain, and the performance of the backup geolocation algorithm had much larger errors comparable to what we saw. Of the 27 DESIS images that used BRISK for image matching, six scenes had RMSE in the $\mathrm{x}$ and/or $\mathrm{y}$ direction $>30 \mathrm{~m}$. Given that DESIS rides on the ISS yielding variable overpass times, we suggest the possibility of simulating multiple terrain shadow patterns to improve the likelihood of geolocation success.

4.2 Limitations of Quality-2 masks: Despite strict application of DESIS QA data, we uncovered some limitations in the Quality-2 masks. Figure 5 shows a close-up of a region in Figures 6-8. Note the area in Figures 7 and 8 where the false color composite (fcc) of vegetation indices yields a dark blue "haze" that appears to result from a cloudy region missed by the quality screening steps.

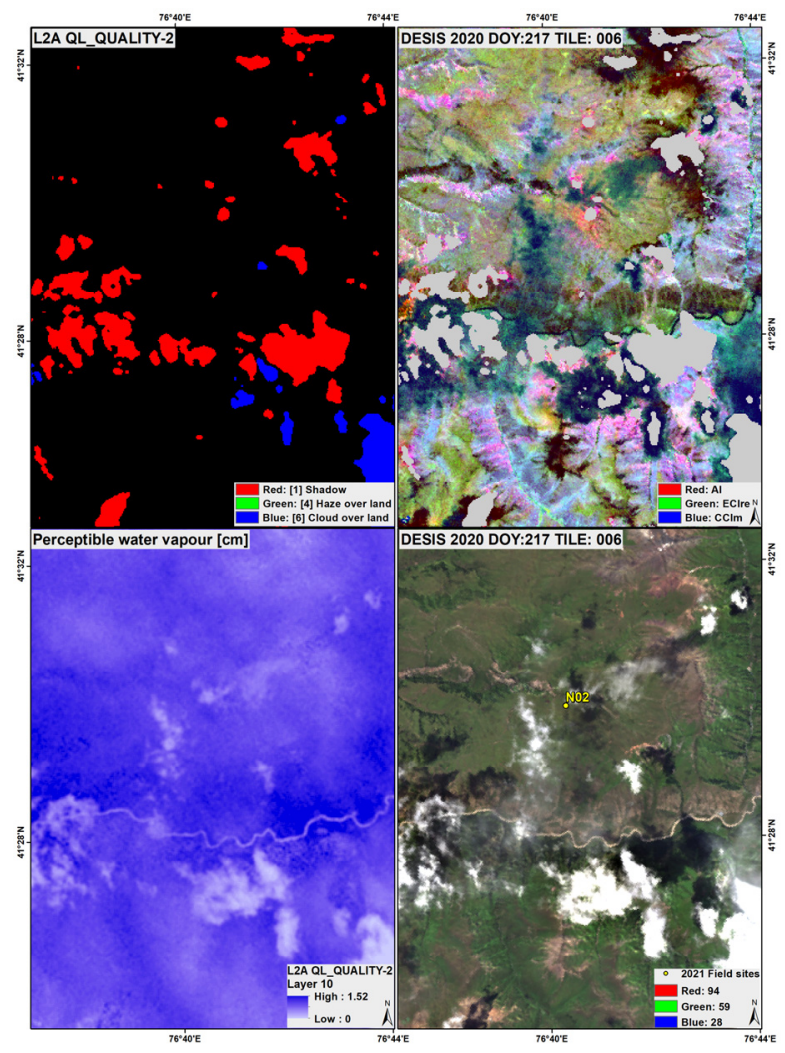

Figure 5: Illustration of Quality-2 omissions. Top left panel is a false color composite (fcc) of three masks layers with shadows in red, haze over land in green, and cloud over land in blue. Top right panel is an fcc of three vegetation indices with quality mask in grey. Bottom left panel is the perceptible water layer of the DESIS Quality-2 data. Bottom right panel displays a DESIS true color composite. Note that the dark blue "haze" in the vegetation index fcc (top right) reveals a larger area of lower quality DESIS data than the Quality-2 masks identify.

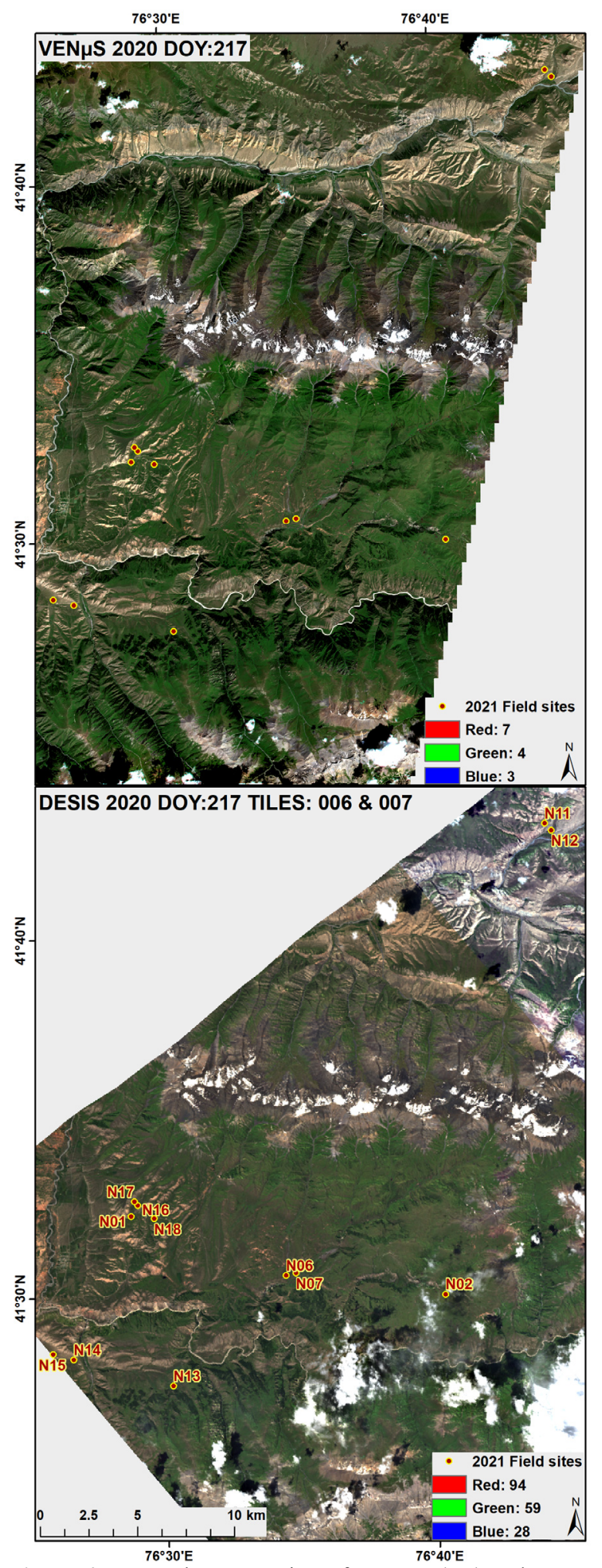

Figure 6: True color composites of VEN $\mu \mathrm{S}$ (top) and DESIS (bottom) on day of year 217 in 2020. Note the location of the centers of the 2021 transects and their labels appear as red circles with yellowing outlining. Note the cloudy area west and southwest of transect center N02 is discussed in section 4.2. 


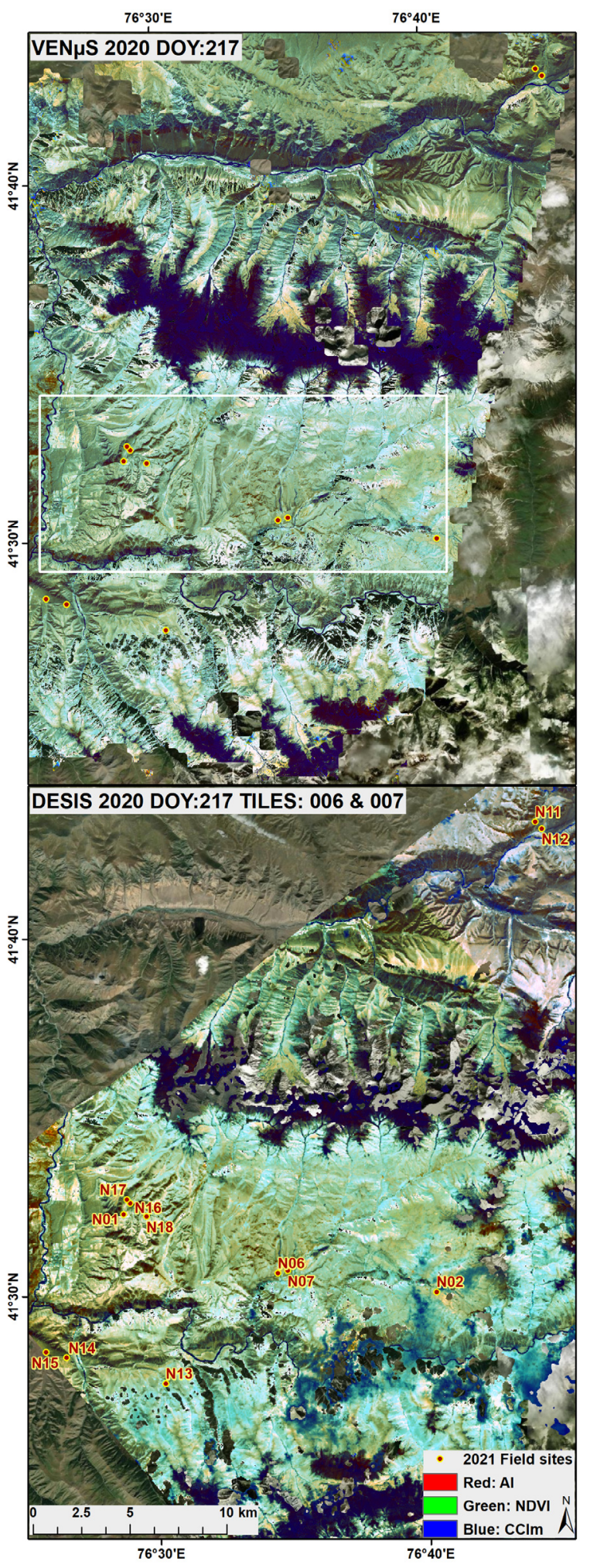

Figure 7: False color composites of VEN $\mu$ S (top) and DESIS (bottom) on day of year 217 in 2020. This fcc features NDVI displayed in green. White rectangle outlines the area sampled for the scatterplots. The dark blue "haze" west and southwest of transect center N02 is discussed in section 4.2.

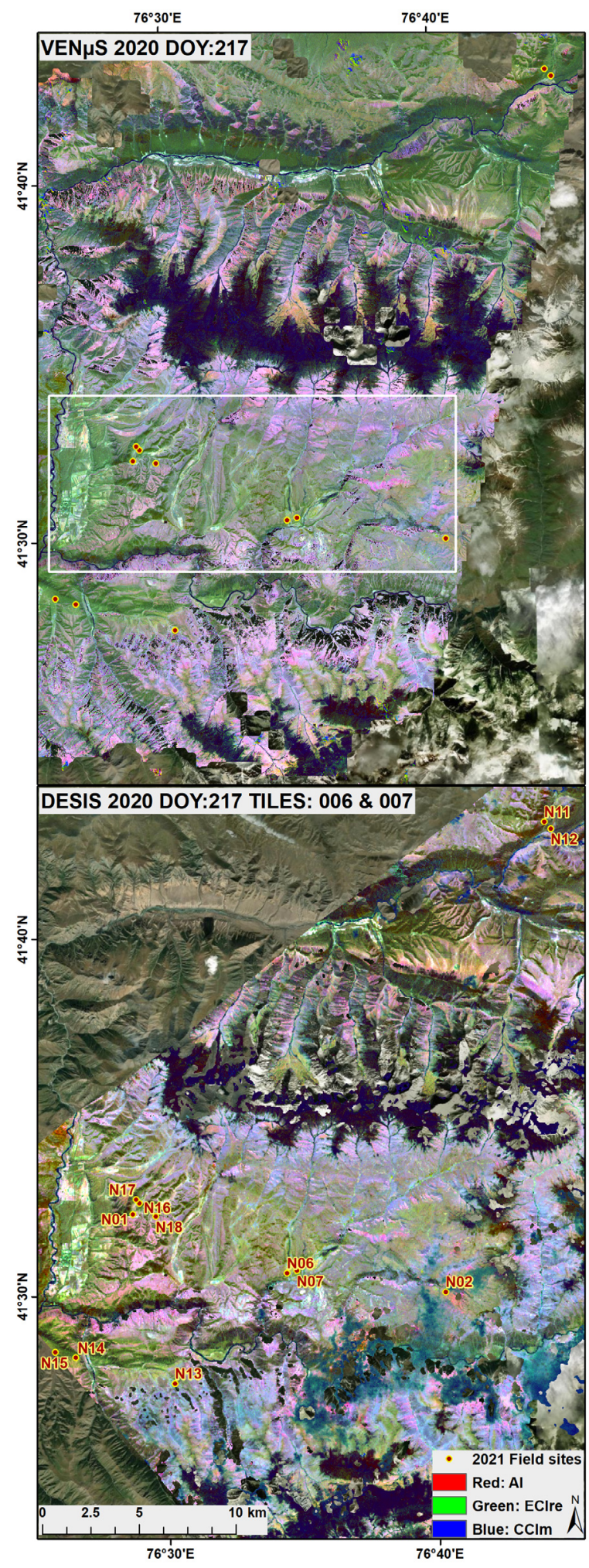

Figure 8: False color composites of VEN $\mu$ S (top) and DESIS (bottom) on day of year 217 in 2020. This fcc features ECIre displayed in green. White rectangle outlines the area sampled for the scatterplots. The dark blue "haze" west and southwest of transect center N02 is discussed in section 4.2 


\subsection{Comparing landscape visualizations}

4.3.1 True color composites: Figure 6 provides true color composite of VEN $\mu \mathrm{S}$ and DESIS images acquired on the same day-August 4, 2020 - but at different times: The VEN $\mu \mathrm{S}$ overpass occurred near noon (1156 local time) and the DESIS data are from mid-afternoon (1409 local time).

4.3.2 False color composite featuring NDVI: True color composites are familiar and easier to interpret, but fccs that combine spectral information to highlight different aspects of the vegetated land surface can help to characterize spatial heterogeneity of pastures within the landscape. We first display the VEN $\mu \mathrm{S}$ footprint in an fcc that features NDVI (Figure 7), showing anthocyanin index (AI) in red, NDVI in green, and chlorophyll/carotenoid index $(\mathrm{CCIm})$ in blue.

Note the many pixels in both images have been masked to black, particularly in rugged terrain. Moreover, the hues of both landscape visualizations range from light blue and green to white. The white areas indicate higher values of each vegetation index. Note, too, the dark blue "haze" in the DESIS image is not evident in the VEN $\mu \mathrm{S}$ image acquired 133 minutes earlier. The white rectangle outlines the area from which $10 \%$ of the pixels were randomly sampled to generate the scatterplots of 4.3.4.

4.3.3 False color composite featuring ECIre: The second fcc we display swaps out NDVI for ECIre resulting in landscape visualizations that appear very different (Figure 8). Many of the areas that appeared white in Figure 7 appear instead in various shades of magenta in Figure 8. More landscape heterogeneity is evident in Figure 8 compared to Figure 7. This discrepancy arises in part from ECIre not being a normalized index and in part from it using the red-edge portion of the spectrum rather than the red to indicate vegetation. While NDVI tends to lose sensitivity when the canopy leaf area index (LAI) is much above $\sim 2.5$, the red-edge wavelengths penetrate more deeply into the canopy and are less absorbed than the red, resulting in an effectively higher dynamic range under a wider variety of LAIs (Clevers and Gitelson, 2016).

\subsubsection{Scatterplots of vegetation indices:}

Figure 9 displays the scatterplots comparing the DESIS and VEN $\mu \mathrm{S}$ vegetation indices. The color scheme denotes density with yellow-to-white indicating the high relative densities.

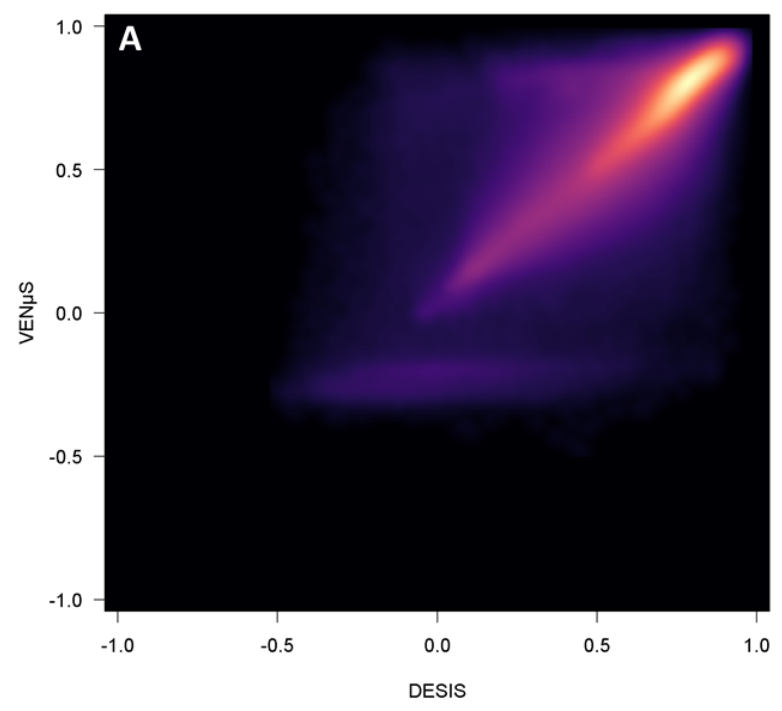

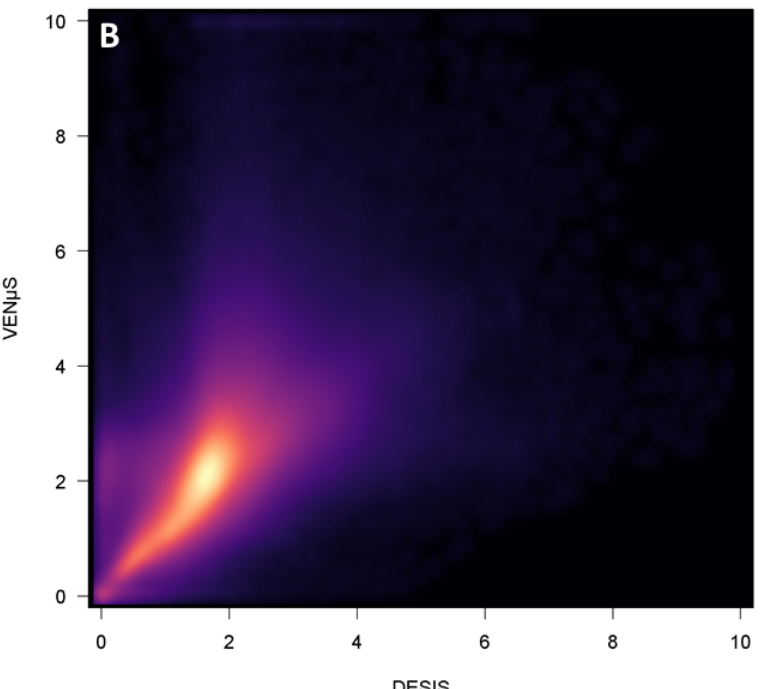
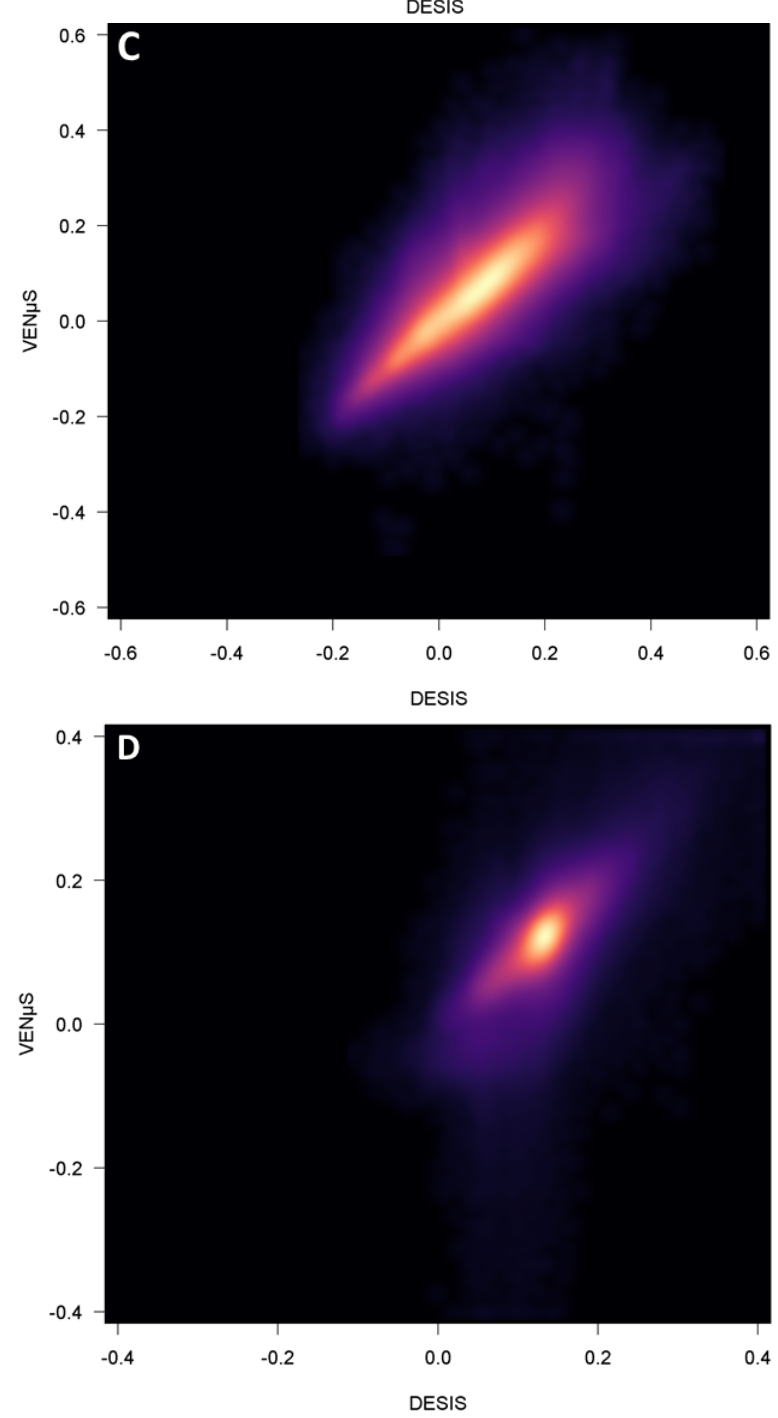

Figure 9: Density scatterplots generated from the data within the white rectangles shown in Figures 7-8. (A) NDVI; (B) AI; (C) CCIm; and (D) ECIre. 
The NDVI scatterplot (Fig. 9A) shows most values skewed high, as expected. In contrast, the AI scatterplot (Fig. 9B) exhibits multiple lobes of lower density indicating some mutual biases. The CCIm scatterplot (Fig. 9C) is more symmetrical and balanced than either the NDVI or AI, but the distribution flares at higher values. The ECIre scatterplot (Fig. 9D) exhibits a smaller range of values with a lower density lobe at lower values.

We resampled the DESIS data to match the finer spatial resolution of the VEN $\mu \mathrm{S}$ data using bilinear interpolation. The Pearson product-moment (Spearman rank) correlation coefficients calculated for the random subsets used in the scatterplots of NDVI, AI, CCIm, and ECIre were $0.860(0.845)$, 0.678 (0.709), $0.855(0.860)$, and $0.686(0.606)$, respectively. All are highly significant $(\mathrm{p}<0.001)$, since $\mathrm{n}$ is very large.

Note that the two vegetation indices that use red-edge bands (AI and ECIre) exhibit substantially lower correlations than the other two indices (NDVI and CCIm). This finding may result from suboptimal spectral rescaling between the DESIS and $\mathrm{VEN} \mu \mathrm{S}$ bands, an artifact arising from the disparities in spatial resolution, or some combination of both.

4.4 Comparing temporal profiles: To construct the temporal profiles of the vegetation indices, we averaged the pixels intersecting with $50 \mathrm{~m}$ radius from each transect center, separately for DESIS and VEN $\mu \mathrm{S}$ data. In each temporal profile, the mean index value is displayed along with the minimum and maximum values of the pixels intersecting the circle circumscribing the transect. We chose maxima and minima to illustrate the uncertainty because (1) we want to emphasize the spatial heterogeneity of the landscape, and (2) there are too few DESIS pixels associated with each $50 \mathrm{~m}$ radius circle to estimate variance reliably.

4.4.1 NDVI as a function of AGDD: Figure 10 provides a VEN $\mu \mathrm{S}$ and DESIS views of the landscape from which we display the temporal profiles. At this spatial extent, landscape features that are recognizable in the $5 \mathrm{~m} \mathrm{VEN} \mu \mathrm{S}$ image appear as vague patches in the $30 \mathrm{~m}$ DESIS image. Comparing the pixels within the transect circles, the $5 \mathrm{~m}$ data clearly captures more spatial heterogeneity than the $30 \mathrm{~m}$ data. Figure 11 shows the temporal profiles of NDVI as a function of AGDD for the three transects. The temporally denser $\mathrm{VEN} \mu \mathrm{S}$ time series show multimodality while the four DESIS data points distributed across the growing season capture only the broad outline of land surface phenology at each transect.

4.4.2 AI, ECIre, and CCIm as functions of AGDD: Figure 12 shows how three complementary vegetation indices portray similar but distinct aspects of land surface phenology at transect N01 during 2020. The important features shared among the $\mathrm{VEN} \mu \mathrm{S}$ index series - but missing in the temporally sparse DESIS data - are the multiple peaks and valleys during the year. Transect N01 (also N16 and N17) are transitional pastures though which livestock herds move in spring on the way to higher elevation summer pastures and again during the fall return to winter quarters. Thus, we interpret the multimodality as resulting not from atmospheric "noise" but from the dense time series capturing actual pasture dynamics arising from transhumance.

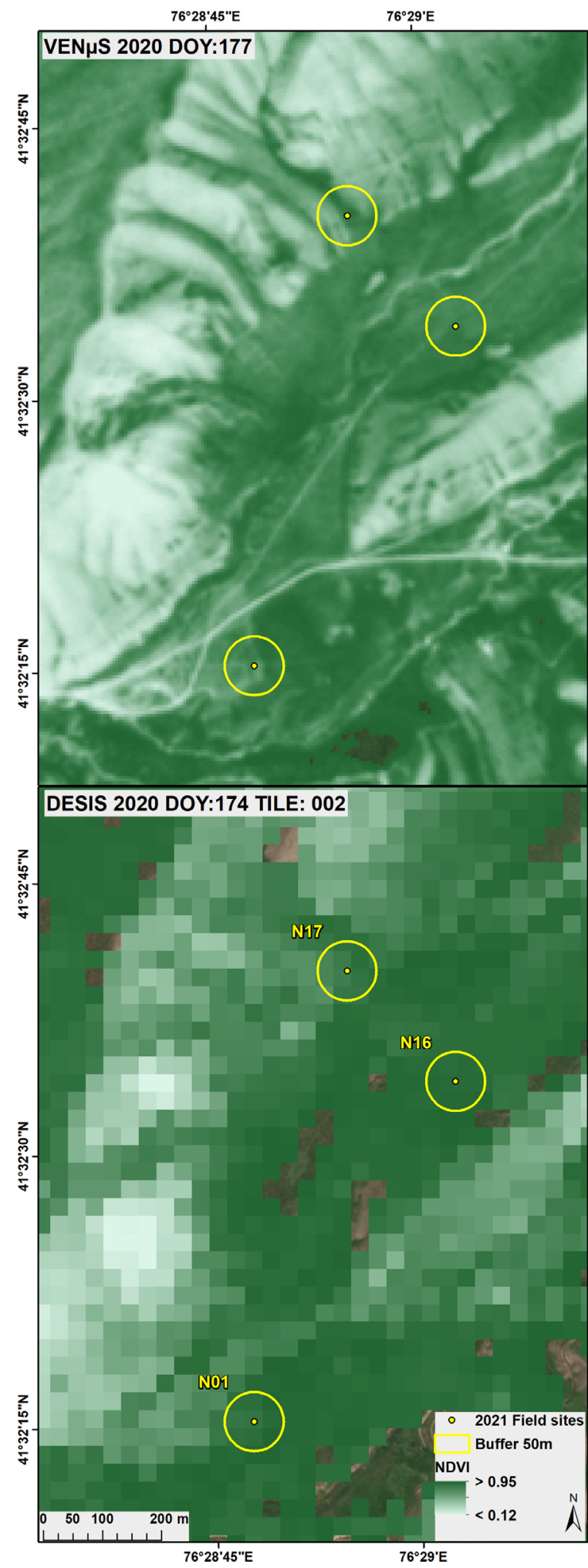

Figure 10: Landscape settings of transects N01, N16, and N17 displayed in NDVI image from VEN $\mu$ S (top) on DOY 177 (June 25, 2020) and DESIS (bottom) on DOY 174 (June 22, 2020). The circles show a $50 \mathrm{~m}$ radius from the transect centers. Temporal profiles average the pixels intersecting the circles. 
NDVI 2020 Site: N17

$$
\text { - DESIS_VENHS A VENHS }
$$

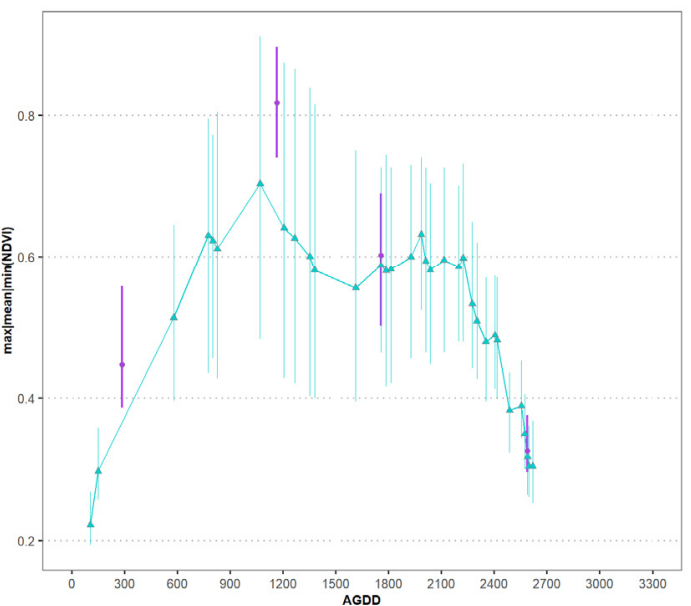

NDVI 2020 Site: N16

- DESIS_VENHS A VENHS

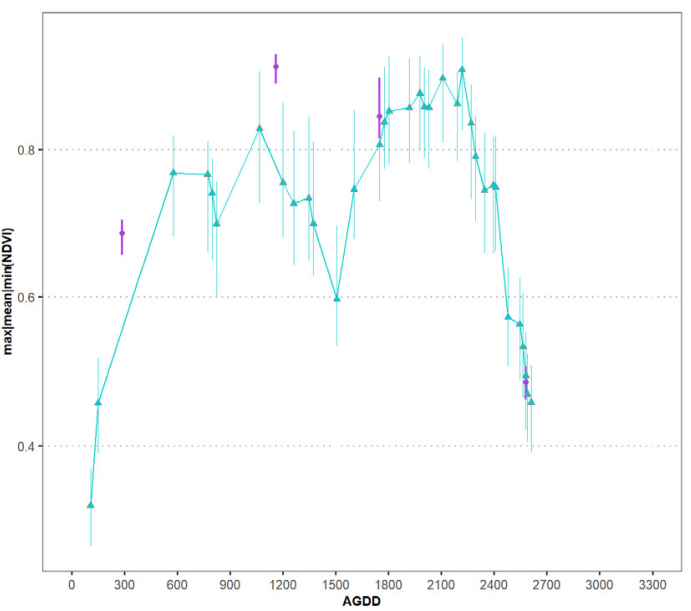

NDVI 2020 Site: N01

- DESIS_VENHS A VENHS

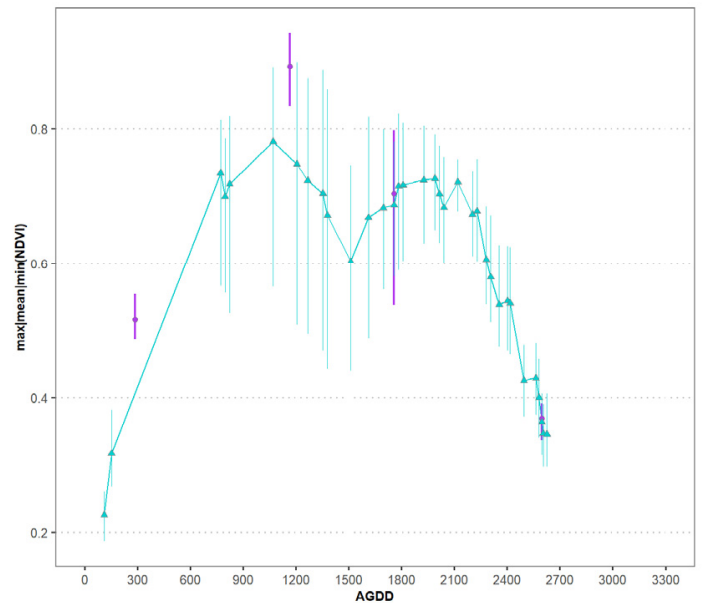

Figure 11: DESIS and temporal profiles of NDVI as a function of AGDD in 2020 for transects N17 (top), N16 (middle), and
N01 (bottom). NDVI profiles show the transect $\mathrm{VEN} \mu \mathrm{S}$ means with transect minimum and maximum in the error bars.

\section{CONCLUSION}

Our exploration of DESIS data in comparison with the high spatial and temporal resolution time series from VEN $\mu S$ has revealed some limitations in the DESIS geolocation in rugged terrain and in the DESIS Quality-2 masks. In addition, the higher temporal resolution time series was able to reveal important transient dynamics in highland pastures that the handful of DESIS scenes could not capture. This result is not surprising. However, the comparative landscape visualizations (Figures 6-8) and the density scatterplots (Figure 9) demonstrate the DESIS data can capture some of the spatial heterogeneity of landscape features with reasonable fidelity, albeit not at the fine spatial resolution of VEN $\mu S$ (cf. Figure 10). Yet, the VEN $\mu S$ dataset is very limited in spatial extent and temporal duration. Thus, we are encouraged to investigate further the DESIS acquisitions outside of the $\mathrm{VEN} \mu \mathrm{S}$ footprint to characterize landscape spatial heterogeneity in the high elevation pastures in other parts of rural Kyrgyzstan.

\section{ACKNOWLEDGEMENTS}

This research was supported in part by the NASA LCLUC Program (80NSSC20K0411).

\section{REFERENCES}

Clevers, J.G.P.W., Gitelson, A.A., 2013. Remote estimation of crop and grass chlorophyll and nitrogen content using red-edge bands on Sentinel-2 and -3. Int. J. Appl. Earth Obs. Geoinf. 23, 344-351. doi.org/10.1016/j.jag.2012.10.008

de Beurs, K.M., Henebry, G.M., Owsley, B.C., Sokolik, I.N., 2018. Large scale climate oscillation impacts on temperature, precipitation and land surface phenology in Central Asia. Environ. Res. Lett. 13, 065018. doi.org/10.1088/17489326/aac4d0

Dubovyk, O., Landmann, T., Dietz, A., Menz, G., 2016. Quantifying the impacts of environmental factors on vegetation dynamics over climatic and management gradients of Central Asia. Remote Sens. 8, 600. doi.org/10.3390/rs8070600

Gamon, J.A., Huemmrich, K.F., Wong, C.Y.S., Ensminger, I., Garrity, S., Hollinger, D.Y., Noormets, A., Peñuelas, J., 2016. A remotely sensed pigment index reveals photosynthetic phenology in evergreen conifers. Proc. Natl. Acad. Sci. 113, 13087-13092. doi.org/10.1073/PNAS.1606162113

Gitelson, A.A., Keydan, G.P., Merzlyak, M.N., 2006. Threeband model for noninvasive estimation of chlorophyll, carotenoids, and anthocyanin contents in higher plant leaves. Geophys. Res. Lett. 33. doi.org/10.1029/2006GL026457

Groisman, P., Bulygina, O., Henebry, G.M., Speranskaya, N., Shiklomanov, A., Chen, Y., Tchebakova, N., Parfenova, E., Tilinina, N., Zolina, O., Dufour, A., Chen, J., John, R., Fan, P., Mátyás, C., Yesserkepova, I., Kaipov, I., 2018. Dryland belt of Northern Eurasia: Contemporary environmental changes and their consequences. Environ. Res. Lett. 13, 115008. doi.org/10.1088/1748-9326/aae43c

Kulikov, M., Schickhoff, U., Borchardt, P., 2016. Spatial and seasonal dynamics of soil loss ratio in mountain rangelands of 
south-western Kyrgyzstan. J. Mt. Sci. 13, 316-329. doi.org/10.1007/s11629-014-3393-6

Tomaszewska, M.A., Henebry, G.M., 2021. Remote Sensing of Pasture Degradation in the Highlands of the Kyrgyz Republic: Finer-Scale Analysis Reveals Complicating Factors. Remote Sens. 2021, Vol. 13, Page 3449 13, 3449. doi.org/10.3390/RS13173449

Tomaszewska, M.A., Henebry, G.M., 2018. Changing snow seasonality in the highlands of Kyrgyzstan. Environ. Res. Lett. 13, 065006. doi.org/10.1088/1748-9326/aabd6f

Tomaszewska, M.A., Nguyen, L.H., Henebry, G.M., 2020. Land surface phenology in the highland pastures of montane Central Asia: Interactions with snow cover seasonality and terrain characteristics. Remote Sens. Environ. 240, 111675. doi.org/10.1016/j.rse.2020.111675

Wang, R., Gamon, J.A., Emmerton, C.A., Springer, K.R., Yu, R., Hmimina, G., 2020. Detecting intra- and inter-annual variability in gross primary productivity of a North American grassland using MODIS MAIAC data. Agric. For. Meteorol. 281, 107859. doi.org/10.1016/J.AGRFORMET.2019.107859

Wang, Y., Yue, H., Peng, Q., He, C., Hong, S., Bryan, B.A., 2020. Recent responses of grassland net primary productivity to climatic and anthropogenic factors in Kyrgyzstan. L. Degrad. Dev. 31, 2490-2506. doi.org/10.1002/LDR.3623

Zhumanova, M., Mönnig, C., Hergarten, C., Darr, D., WrageMönnig, N., 2018. Assessment of vegetation degradation in mountainous pastures of the Western Tien-Shan, Kyrgyzstan, using eMODIS NDVI. Ecol. Indic. 95, 527-543. doi.org/10.1016/j.ecolind.2018.07.060
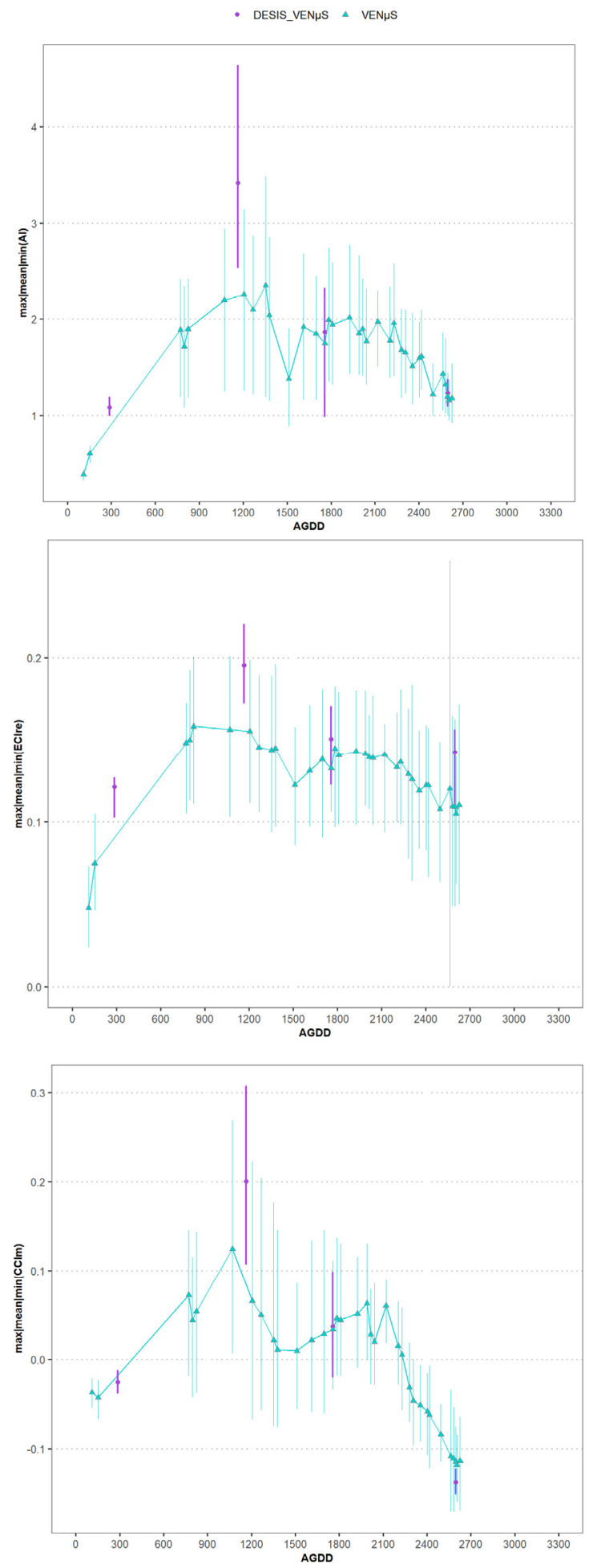

Figure 12: Temporal profiles at transect N01 during 2020 for (top) the anthocyanin index (AI), (middle) the erectophile chlorophyll index using the red-edge (ECIre), and (bottom) the chlorophyll/carotenoid index for MODIS bands (CCIm). Note that error bars display the transect minimum and maximum at each time point. 